\title{
Extensor digitorum brevis manus: A case of fourth-compartment syndrome
}

\author{
RC Mahabir MD ${ }^{1}$, JS Williamson MD FRCSC ${ }^{2}$, DG Williamson MD FRCSC ${ }^{2}$, EL Raber MD FRCPC ${ }^{3}$
}

RC Mahabir, JS Williamson, DG Williamson, EL Raber. Extensor digitorum brevis manus: A case of fourth-compartment syndrome. Can J Plast Surg 2003;11(3):149-152.

The presence of an extensor digitorum brevis manus represents a variation of the normal anatomy of the fourth extensor compartment of the wrist. It usually presents as a swelling on the dorsum of the wrist and is often inaccurately diagnosed. An awareness of its existence and of its characteristic appearance on diagnostic imaging studies is the basis for diagnosis. Symptomatic cases require division of the extensor retinaculum or excision of the muscle, depending on subtype, while asymptomatic cases require no intervention.

Key Words: Anomalous extensors; Extensor digitorum brevis manus; EDBM; Fourth-compartment syndrome

\section{Un muscle extenseur commun court des doigts : Un syndrome de la quatrième loge}

La présence d'un muscle extenseur commun court des doigts représente une variation de l'anatomie normale de la loge du quatrième extenseur du poignet. D'ordinaire, cette manifestation prend la forme d'un œè̀me du dos du poignet. Elle est souvent mal diagnostiquée. La prise de conscience de son existence et de son apparence caractéristique à la visualisation diagnostique constitue le fondement du diagnostic. En présence de cas symptomatiques, il faut diviser le ligament annulaire ou exciser le muscle, selon le sous-type, tandis que les cas asymptomatiques n'exigent aucune intervention.
$\mathrm{T}^{\mathrm{s}}$ he vast majority of variations of the extensor tendons of the hand are asymptomatic throughout life, but their importance in hand surgery has been documented (1-4). The variations are often found incidentally at the time of surgery and at the time of diagnostic imaging (5). On occasion they may be associated with dorsal wrist pain, but a direct correlation is often difficult in the presence of other pathology, such as a ganglion or synovitis (6-9).

First described by Albinus in 1734, as "muscles extensor brevis digiti indicis vel medii" (1), the existence of this anomalous muscle was questioned owing to its infrequent clinical presentation. Various anatomical descriptions persisted, but in 1866 Macalister (10) coined the term 'extensor digitorum brevis manus' (EDBM). The first clinical correlate was reported in 1926 (11). Since then, over 100 articles have been published on the topic leading to the development of two separate classifications. With incidences reported to be between $1 \%$ and $9 \%$ (11-16), the occurrence of this muscle should not surprise the anatomist or hand surgeon. In light of the high incidence and the lack of symptomatic case reports, the majority of EDBM cases must remain asymptomatic.

A case of EDBM in association with an intraosseous ganglion of the lunate as a cause of fourth-compartment syndrome is reported. A review of the literature and current imaging techniques are presented to underline the clinical implications of this anomalous extensor muscle.

\section{CASE PRESENTATION}

A 36-year-old, right-hand dominant woman was referred with left wrist pain after falling on her outstretched hand. The ini- tial swelling and pain was managed with physiotherapy. However, the pain persisted over the central dorsal aspect of the wrist and she was unable to return to work. Although increased with most hand movements, the pain was worst with wrist flexion. There was no significant past medical history.

On examination, she had a normal resting posture and range of motion. Palpation found dorsal tenderness centrally over the lunate. There was also a dorsal soft tissue mass clinically suspected to be hypertrophied extensor tenosynovium.

Radiographs of the left wrist demonstrated a well-circumscribed lytic defect in the dorsal aspect of the lunate and a mild soft tissue swelling noted over the dorsum of the wrist.

An axial computed tomographic (CT) scan of both wrists was subsequently performed, that revealed two distinct findings; best seen on specific bone windows, the CT confirmed and better characterized the lytic lesion in the left lunate. The lesion, which measured $6 \times 5 \times 5 \mathrm{~mm}$, did not demonstrate any aggressive features and had very fine sclerotic margins. However, it did have an area of breech of the cortex at the lunate triquetrial articulation dorsally.

Dedicated soft tissue windows also revealed an asymmetric soft tissue attenuation 'mass-like' area at the dorsal aspect of the left wrist. This area was at the level of the carpal bones. It appeared to be related to the extensor tendons/sheath, but not the lytic lesion in the lunate. The area was elongated, following the course of the extensor tendon sheath and was isoattenuating with surrounding muscles. (Figure 1).

Magnetic resonance imaging (MRI) confirmed the presence of a $7 \mathrm{~mm}$ subchondral cyst in the dorsal radial aspect of the left lunate. It also confirmed and better characterized the

\footnotetext{
${ }^{1}$ Division of Plastic Surgery, University of Calgary; ${ }^{2}$ Division of Plastic Surgery, Kelowna General Hospital, Okanagan Plastic Surgery Centre and the University of British Columbia; ${ }^{3}$ Department of Diagnostic Imaging, University of Calgary and the Foothills Medical Centre

Correspondence: Dr Raman C Mahabir, Foothills Medical Centre, Department of Surgery, 1403 29th Street NW, Calgary, Alberta T2N 2T9.

Telephone 403-670-1110, fax 403-270-0148, e-mail raman_chaos@hotmail.com
} 


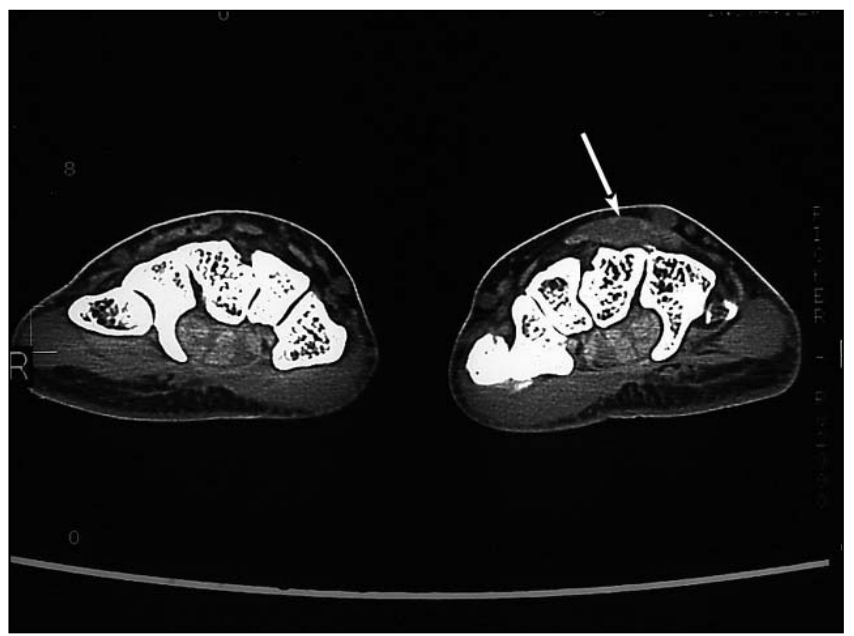

Figure 1) Axial CT of both wrists. Asymmetric soft tissue attenuation "mass-like" area at the dorsal aspect of the left wrist (white arrow)

$1 \mathrm{~cm}$ soft tissue 'mass' visible along the extensor tendons of the index and long fingers. The apparent 'mass' was homogenous and iso-intense, with muscle on all sequences (intermediate to low $\mathrm{T} 1$ and $\mathrm{T} 2$ signal intensity) and did not demonstrate any enhancement; a classic finding for an anomalous muscle. The adjacent tendons were of normal size and signal. There was no other evidence of a discrete mass or any abnormal fluid accumulation. The imaging features and location were classic for EDBM (17) (Figure 2).

It was felt that both the lesion in the lunate and the extensor tenosynovitis could be responsible for the patient's symptoms. Unfortunately, nonoperative management with splinting and anti-inflammatory therapy failed. Extensor tenosynovectomy plus curettage and bone grafting of the lunate were recommended.

At the time of surgery, extensor tenosynovitis was seen around the fourth extensor compartment and a tenosynovectomy was undertaken. An anomalous muscle belly was found originating from the dorsal wrist capsule at the distal extensor retinaculum, deep to the extensor digitorum communis tendons and coursing distally to insert into the dorsoulnar extensor hood on the index finger. Extensor indicis proprius (EIP) was absent. Recognized as an EDBM, it was decided not to excise the muscle but to increase the calibre of the fourth extensor compartment via a stairstep lengthening of the extensor retinaculum. The lunate intraosseous ganglion was curetted and a distal radius bone graft was packed into the defect.

Follow-up demonstrated progressive ossification of the lunate defect. Wrist and digital range of motion and pain recovered with physiotherapy.

\section{DISCUSSION}

Gama (18) randomly examined 3404 adults and found 38 cases of EDBM for an incidence of $1.1 \%$. Occurring bilaterally in one-third of the reported cases, EDBM shows no difference in incidence between the right and left hands or between sexes $(12,18-20)$. Various descriptions of the origin of the muscle exist. It was best described by Ogura et al (20) as arising from the posterior radiocarpal ligaments near the lunate, as far prox- imal as the distal margin of the radius, and without direct attachment to the carpal bones. The muscle insertion is reported to be similar to that of the EIP (16). This suggests that the EDBM is derived from an extrinsic muscle. There are two classification systems at present, both based on the presence or absence of the EIP as well as the origin and insertion patterns $(19,20)$.

Clinically, EDBM usually presents as a prominent, firm mass on the dorsal wrist that may be painful when the fingers are actively extended against resistance $(13,18-22)$ or when the palm is pushed against a table with extension of the wrist (20). The diagnosis is most often confused with a dorsal wrist ganglion or synovial pathology. However, a ganglion, synovitis or other wrist pathology may coexist, as seen in this case. Differentiation from an anomalous EIP (aEIP) is more difficult, but according to Ritter and Inglies (23), extensor indicis proprious syndrome can be ruled out. In that syndrome, the aEIP is constricted by the extensor retinaculum as it passes distal to the fourth compartment in full wrist flexion. In constrast, the EDBM muscle belly lies distal to the distal edge of the extensor retinaculum and extends to the midpoint of the second and third metacarpals. Previously, direct electromyogram has been recommended to diagnose and subtype EDBM (24). The MRI appearance, including signal intensities and lack of enhancement, combined with the classic anatomic location are characteristic for EDBM. Thus, with MRI, it is possible to differentiate EDBM from a neoplasm or ganglion. Sub-typing of EDBM is difficult with MRI and this classification is of little practical importance. Surgery is usually for the relief of pain.

EDBM usually causes little or no pain, and in these patients surgical intervention should be avoided. Patient reassurance is often sufficient to relieve distress. The muscle should not be seen as an excess structure but as a synergistic component of the EIP when present or as compensation when the EIP is absent. Conservative treatment, such as short-wave diathermy, paraffin baths, immobilization and anti-inflammatory drugs, have been used with limited success $(19,21,25)$. If the symptoms are severe and surgical intervention is warranted, then the classification can be made at the time of surgery based on the presence or absence of the EIP. In cases in which the EIP is completely absent, division or resection of the extensor retinaculum is recommended. Although division of the retinaculum may provide relief when the EIP is present, some authors (19) recommend excision of the EDBM leaving the EIP tendon intact. A case review found that $75 \%$ of patients required excision of the muscle belly if symptomatic (19).

A recent article proposed the new term, "fourth-compartment syndrome," to describe chronic dorsal wrist pain of the fourth extensor compartment (26). It listed the five main causes as ganglion, EDBM, aEIP, tenosynovitis and anomaly or deformity of the carpal bones. As opposed to the concept that the pain results from muscle belly compression, the authors suggested it may be due in part to compression of the posterior interosseous nerve either directly or indirectly.

Diagnosis of EDBM can be made clinically and confirmed with MRI. It should not be misinterpreted as a soft tissue tumour. At the time of surgery, management is determined by the presence or absence of an EIP. It involves the release of the fourth extensor compartment and in cases where an EIP is present, possible excision of the EDBM if further decompression is required. 

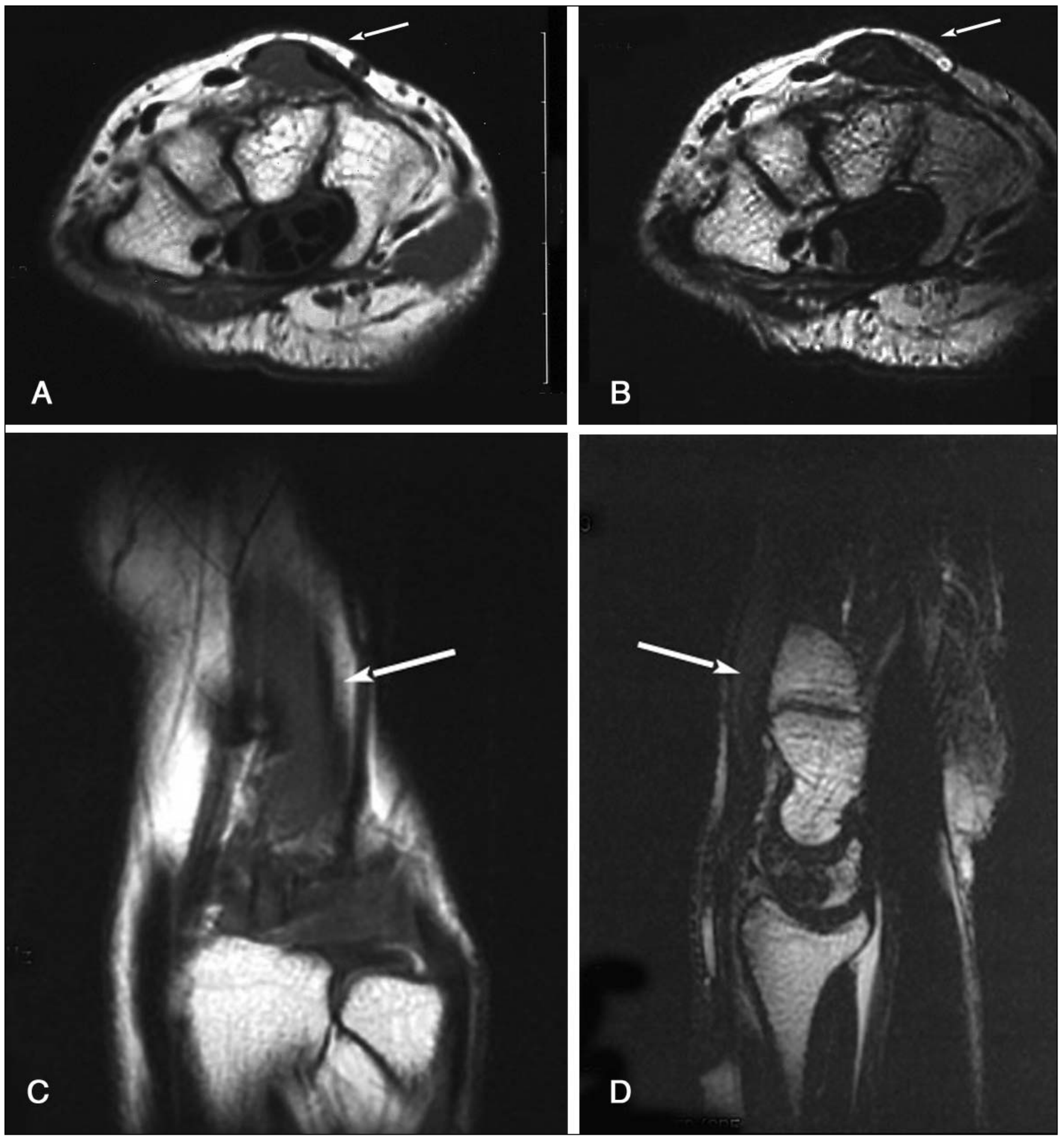

Figure 2) Axial T1 (A) and Axial T2 (B) magnetic resonance imaging (MRI) of the left wrist, at the same level at the computed tomography (CT). Confirms that the 'mass-like' area is iso-intense with surrounding muscle and has a characteristic appearance and location of an anomalous muscle (white arrow); Coronal T1(C) and Sagittal T2 (D) MRIof the left wrist, at the same level at the CT. Confirms that the 'mass-like' area is iso-intense with surrounding muscle and has a characteristic appearance and location of an anomalous muscle (white arrow)

\section{REFERENCES}

1. Tan ST, Smith PJ. Anomalous extensor muscles of the hand:

A review. J Hand Surg 1999;24(Suppl A):449-55.

2. Mestdagh H, Bailleul JP, Vilette B, Bocquet F, Depreux R.

Organization of the extensor complex of the digits. Anat Clin 1985;7:49-53.

3. Schenck RR. Variations of the extensor tendons of the fingers:

Surgical significance. J Bone Joint Surg 1964;46(Suppl A):103-10.
4. Leslie DR. The tendons of the dorsum of the hand. Aust N Z J Surg 1954;23:253-6

5. Zeiss J, Guilliam-Haidet L. MR demonstration of anaomalous muscles about the volar aspect of the wrist and forearm. Clin Imaging 1996;20:219-21

6. Dostal GH, Lister GD, Hutchinson D, Mogan JV, Davis PH. Extensor digitorum brevis manus associated with a dorsal wrist 
ganglion: A review of five cases. J Hand Surg 1995;20:35-7.

7. Cheng JCY, Hung LK. An unusual cause of wrist pain. J Hand Surg 1986;11(Suppl B):221-2.

8. Constantian MB, Zuelzer WA, Theogaraj SD. The dorsal ganglion with anomalous muscles. J Hand Surg 1979;4:84-5.

9. Spinner M, Olshansky K. The extensor indicis proprius syndrome: A clinical test. Plast Reconstr Surg 1973;51:134-8.

10. Macalister A. Note on muscular anomalies in human anatomy. Proc R Irish Acad 1866;9:444-67.

11. McGregor Al. A contribution to the morphology of the thumb. J Anat 1926;60:259-73.

12. Stith JS, Browne PA. Extensor digitorum brevis manus: a case report and a review. Hand 1979;11:217-223.

13. Dunn CAW, Evarts CM. The extensor digitorum brevis manus muscle: a case report. Clin Orthop 1963;28:210-212.

14. Souter WA. The extensor digitorum brevis manus. Br J Surg 1966;53:821-823.

15. Wood J. On some varieties in human myology. Proc R Soc Lond 1864:13:229-303.

16. Cauldwell EW, Anson BJ, Wright RR. The extensor indicis proprius muscle: a study of 263 consecutive specimens. Q Bull Northwest Univ Med School 1943;17:267-269.
17. Anderson MW, Benedetti P, Walter J, Steinberg DR. MR appearance of the extensor digitorum manus brevis muscle: a pseudotumor of the hand. Am J Roentgenol 1995;164:1477-1479.

18. Gama C. Extensor digitorum brevis manus: A report on 38 cases and a review of the literature. J Hand Surg 1983;8:578-582.

19. Ross JA, Troy CA. The clinical significance of extensor digitorum brevis manus. J Bone Joint Surg 1969;51B:473-478.

20. Ogura T, Inoue H, Tanabe G. Anatomic and clinical studies of the extensor digitorum brevis manus. J Hand Surg 1987;12A:100-107.

21. Jones BV. An anomalous extensor indicis muscle. J Bone Joint Surg 1959;41B:763-765.

22. da Gama CC. Musculus extensor digitorum brevis manus. Int Surg 1976;61:39-40

23. Ritter WA, Inglis AE. The extensor indicis proprius syndrome. J Bone Joint Surg [Am] 1965:51:645-648.

24. Egawa T, HashimotoK. An anomalous exensor indicis muscle A case report. Bull Hosp J Dis Orthop Inst 1966;27:116-119.

25. Reef TC, Brestin SG. The extensor digitorum brevis manus. Hand 1972;4:263-264.

26. Hayashi H, Kojima T, Fukumoto K. The fourth-compartment syndrome; its anatomical basis and clinical cases. Handchir Mikrochir Plast Chir 1999;31:61-65. 